\title{
O movimento de cargas elétricas em um fio condutor: cuidados com as simplificações das simulações no ensino de física
}

The movement of electrical charges in a conducting wire: the care with the simplifications of simulations in physics teaching

\author{
C. D. Barbosa*; I. S. Lima; T.C Martins; M. L. das Chagas; F. C. L. Ferreira \\ Programa de Pós-Graduação em Ensino de Física, Universidade Federal do Sul e Sudeste do Pará, 68500-000, \\ Marabá - PA, Brasil. \\ *cairodb@gmail.com
}

(Recebido em 05 de setembro de 2016; aceito em 18 de setembro de 2016)

\begin{abstract}
Com o desenvolvimento da tecnologia ocorreu uma inovação nos métodos de experimentação dos conteúdos de Física em sala de aula. Atualmente dispomos de diversos programas que facilitam as demonstrações de fenômenos físicos, ampliando a compreensão e aprendizagem. Este trabalho tem como objetivo apresentar os cuidados com as simplificações existentes em alguns simuladores que tratam do movimento de cargas elétricas em um fio condutor. Desse modo, pode-se demonstrar que uma corrente elétrica, simulada através de alguns destes softwares podem levar o aluno a ter uma ideia distorcida dos conceitos físicos abordados. Na utilização de qualquer simulador no ensino de Física é necessário que o professor explique para os seus alunos as simplificações existentes que gera uma compressão equivocada. Os simuladores avaliados neste trabalho estão disponíveis gratuitamente no site da Phet colorado (htpp://phet.colorado.edu/pt_BR/). Para demonstrar as possíveis consequências do uso incorreto de alguns simuladores nos assuntos de Física como, por exemplo, o "Movimento de cargas elétricas em um fio condutor" foram escolhidos três simuladores: Sinal de Circuito, Kit de construção de circuito (DC) e Circuito Bateria-Resistor. Nos resultados, observou-se que as simplificações dificulta a aprendizagem dos alunos, contribuindo para interpretações errôneas na utilização de cada simulador. Portanto se faz necessário, que os professores fiquem atentos na utilização de softwares em sala de aula para que o aprendizado não seja comprometido por meio de simplificações dos experimentos.
\end{abstract}

Palavras-chave: simulações, ensino de física, cargas elétricas.

With the development of the technology occurred an innovation in the methods of experimentation of physics content in the classroom. Currently we have several programs that facilitate demonstrations of physical phenomena, increasing understanding and learning. This paper aims to present the care with existing simplifications in some simulators dealing with the movement of electric charges in a thread. Thus, it can be shown that an electric current, simulated through some of these softwares can lead the student to have a distorted idea of the addressed physical concepts. When using any simulator in teaching physics is necessary for the teacher explain to their students the existing simplification that generates a wrong compression. Simulators used in this work are available for free at the Colorado Phet site (htpp: //phet.colorado.edu/pt_BR/). To demonstrate the possible consequences of the incorrect use of some simulations in physics subjects such as the "movement of electric charges in a conductor wire" were chosen three simulators: Circuit Sign, Circuit Construction Kit (DC) and circuit battery-Resistor. In the results, it was observed that the simplifications hinders student learning, contributing to misinterpretations in the use of each simulator. Therefore it is necessary that teachers stay tuned on the use of softwares in the classroom so that learning is not compromised through simplifications of the experiments.

Keywords: simulations, teaching physics, electrical charges

\section{INTRODUÇÃO}

O ensino de física, ao longo dos anos, tem carregado um histórico negativo de aprendizagem, a repetência da série e notas baixas é uma característica singular nesta disciplina. Entende-se que um dos indicadores desses números é a falta de experimentações utilizadas em sala de aula. 
Segundo Moraes (2000) [1] de modo convergente, no discurso de professores e alunos, o uso de atividades experimentais como estratégia de ensino de Física é uma das maneiras mais eficazes de se minimizar as dificuldades de aprender e de ensinar Física de modo significativo e consistente.

Com a ampliação da tecnologia, inovaram-se também os métodos de demonstrações de experimentos em sala, diversos são os simuladores que facilitam os esclarecimentos de fenômenos físicos, estes, portanto, são oportunidades pedagógicas relacionadas aos recursos visuais disponíveis pelo uso de computadores que ampliam o ensino e aprendizagem.

No entanto, o principal risco deste uso está em não esclarecer que a simulação é um modelo aproximado da realidade, pois são situações observáveis da vida real, porém modeláveis por programas computacionais, onde o aluno poderá correlacionar os conceitos vistos em sala de aula e aplicá-los com uso dos softwares [2].

O significado da palavra modelo é uma representação, uma interpretação simplificada da realidade, ou uma interpretação de um fragmento de um sistema segundo uma estrutura de conceitos. E na sala de aula, esse contexto deve ser esclarecido, enfatizando a fragmentação da realidade alterada na simulação.

Este trabalho tem como objetivo apresentar os cuidados com as simplificações existentes nas simulações no Ensino de Física em relação aos movimentos das cargas elétricas em um fio condutor, uma vez que alguns podem descaracterizar alguns dos comportamentos das cargas elétricas.

Antes da aplicação do simulador, os professores precisam realizar orientações dando ênfase em cada fator de mudança que possa gerar uma compressão diferenciada, destacando ainda que se trata de um modelo de como o fenômeno acontece. Para mostrar as consequências do uso incorreto de alguns simuladores no ensino de Física, foram selecionados três de disponibilização gratuita na plataforma virtual: simulador "Sinal de Circuito", simulador "Kit de construção de circuito (DC)" e simulador "Circuito Bateria-Resistor".

Descrevem-se nos resultados as simplificações e os exageros de cada simulador e a postura pedagógica que o docente deve aplicar para que o aprendizado não seja comprometido.

\section{CONTEXTUALIZAÇÃO}

\subsection{A FÍSICA NO ENSINO MÉDIO}

Para Moreira e Masini (2002) [3], as perspectivas do Ensino de Física no Brasil são definidas por dois documentos: as Diretrizes Curriculares para os Cursos de Graduação e os Parâmetros Curriculares Nacionais para o Ensino Médio.

Para ter um ensino significativo, os conceitos, competências e metodologias devem ter o objetivo da promoção do protagonismo juvenil e a formação autônoma do aluno: "[...] o que a Física deve buscar no ensino médio é assegurar que a competência investigativa resgate $o$ espírito questionador, o desejo de conhecer o mundo em que se habita" [4].

Pensar na qualidade do ensino para Carnoy (2009) [5], está diretamente ligada à qualidade das experiências de aprendizagem que os alunos vivenciam, assegurando assim uma efetiva aprendizagem em Física.

O cotidiano das pessoas está cercado de fenômenos naturais e de equipamentos tecnológicos cujos princípios são objetos de estudo da Física. Diante de tantas perspectivas, concorda-se no sentido de que:

[...] cada uma destas vertentes tem seu valor, mas também suas limitações e, até mesmo, prejuízos para o ensino da Física, na medida em que forem exclusivas. Julgo que é um erro ensinar Física sob um único enfoque, por mais atraente e moderno que seja. Por exemplo, Física somente sob a ótica da Física do cotidiano é uma distorção porque, em boa medida, aprender Física é justamente, libertar-se do dia a dia. De modo semelhante, ensinar Física apenas sob a perspectiva histórica, também não me parece uma boa metodologia porque para adquirir/construir conhecimentos o ser humano 
normalmente, não precisa descobri-los, nem passar pelo processo histórico de sua construção. Tampouco o microcomputador será um bom recurso metodológico, se for usado com exclusividade, dispensando interação pessoal, a troca, ou negociação, de significados que é fundamental para um bom ensino de Física [3].

Os desafios da prática pedagógica são cada vez maiores e mais complexos na sociedade contemporânea. A urgência de articular os conteúdos da Física com o interesse e a necessidade dos alunos e o compromisso com as transformações técnico-científicas atuais tem sido o foco das preocupações das investigações em ensino de Física [6].

\subsection{O USO DE SIMULADORES NO ENSINO DE FÍSICA}

As simulações virtuais são programas que operam com representações matemáticas através de uma linguagem de programação, que procura apresentar animações que imitam, ou se aproximam de sistemas, sejam reais ou imaginários [7]. Dentre estas existem simulações que o aprendiz apenas a observa sem a possibilidade de interferência e existem as simulações interativas que permitem que o estudante realize uma interação com o modelo simulado.

Dentre os modelos de simulações neste trabalho, optou-se por abordar as simulações interativas devido a maior ludicidade que estas possibilitam nas aulas de Física frente à abordagem de conceitos principalmente abstratos. Estas simulações permitem que o aluno interfira no sistema, alterando parâmetros e assim faça reflexões sobre as implicações de cada alteração realizada e também relações entre as grandezas físicas presentes no fenômeno [8].

Desse modo, através de recurso didático é possível ao aluno, compreender de maneira mais palpável um fenômeno físico complexo e abstrato em vez se usar apenas uma construção mental e sua memória de curto prazo. Portanto, com a utilização de simuladores é possível ampliar a capacidade de imaginação e intuição do aluno [9].

Para Fiolhais e Trindade (2003) [8], as simulações têm a vantagem ainda de permitir que o aluno interaja com modelos de experiências difíceis ou impossíveis de serem realizadas fora do mundo virtual, devido a questões como alta periculosidade, custo elevado, e ocorrerem de maneira demasiadamente lenta ou de forma muito rápida.

\subsection{CUIDADOS COM O USO INCORRETO DE SIMULADORES NA ABORDAGEM DE FENÔMENOS FÍSICOS.}

Mesmo com as diversas vantagens no uso de simulações no ensino de Física, é preciso tomar alguns cuidados. Existem alguns pontos negativos que devem ser considerados no uso deste recurso. Algumas simulações, por exemplo, apresentam exageros nas animações dos fenômenos físicos abordados, outras possuem muitas simplificações, o que pode passar uma ideia distorcida da realidade e assim levar o educando a elaborar interpretações equivocadas [7].

No entanto, o principal alerta do uso incorreto das simulações no ensino de física se deve ao fato de muitos alunos não compreenderem que a simulação se trata apenas de um modelo e assim passam a idealizar que os fenômenos físicos no mundo real acontecem da mesma forma como são apresentados nas simulações. Isto é um entendimento errôneo, pois uma simulação não pode representar fielmente a realidade, ou seja, toda a complexidade de um fenômeno estudado e as interferências que o mesmo sofre do meio [10].

Outra falha cometida na utilização de simulações no ensino se deve ao fato de alguns professores utilizarem estes recursos midiáticos como alternativa a substituição de experimentos reais, às vezes, até mesmo experimentos de simples construção como, por exemplo, um eletroímã ou um circuito em série são trocados por simulações. Tanto os experimentos reais como as simulações virtuais são importantes para o ensino de Física e devem ser utilizadas de forma conjunta [11]. Num experimento real, por exemplo, não é possível ver elétrons se movimentando em um fio condutor, também somente através de uma simulação não é possível ao aluno sentir o aumento de temperatura em um fio devido o Efeito Joule. 
Portanto, no uso de simulações, o educador deve ter a preocupação de explicar para os seus alunos as simplificações do sistema, os exageros, as limitações, os fatores que não foram considerados. Levar os discentes a entenderem que a simulação é apenas um modelo, ou seja, uma aproximação, e que dessa forma não devem fazer suas deduções, questionamentos e hipóteses com base na simulação, mas sim, com base no fenômeno real que está sendo simulado, pois se isso não acontecer, corre-se o risco do educando construir interpretações equivocadas das leis e conceitos físicos abordados [7].

Diante da quantidade destes softwares disponíveis, é importante também que na escolha das simulações o professor realize antes uma avaliação, optando por aquelas que apresentem um modelo o mais próximo possível do sistema original, sem muitas simplificações e de boa qualidade pedagógica [11].

\subsection{O USO DE SIMULAÇÕES NO ESTUDO DO MOVIMENTO DE CARGAS ELÉTRICAS}

Levando em consideração a abstração de alguns fenômenos físicos, como aquele relacionado à eletrodinâmica, optou-se por realizar um estudo sobre alguns programas disponíveis na internet, que simulam o fenômeno de corrente elétrica. Ter o entendimento de como as cargas elétricas se locomovem em um fio condutor é essencial para que o aluno compreenda outros fenômenos como o Efeito Joule, resistividade e condutibilidade de um material.

O estudo de corrente elétrica é um bom exemplo de assunto que o professor necessita de alguns cuidados na hora de usar as simulações virtuais, pois os alunos precisam imaginar algo que não podem visualizar. Dessa forma a simulação, pode facilitar o aprendizado através da ilustração do fenômeno estudado, porém às inúmeras simplificações no modelo pode levar o aluno a fazer interpretações errôneas. No caso da corrente elétrica, o aluno não pode comparar o que esta sendo observado em uma simulação com suas experiências do cotidiano, como acontecem, com outros fenômenos físicos como a simulação do lançamento de uma bola de futebol, por exemplo.

Sendo assim, quando o aluno não vivencia ou observa de forma real o fenômeno físico simulado, o mesmo poderá visualizar mentalmente o fenômeno como é apresentado na simulação. Dessa forma, dentre os simuladores no ensino de Física, aqueles que melhor precisam ser avaliados pelo professor são justamente os que trabalham fenômenos de grande abstração.

\subsection{O COMPORTAMENTO DAS CARGAS ELÉTRICAS EM UM CIRCUITO ELÉTRICO.}

Em um condutor por onde não passa uma corrente, os elétrons de condução se movimentam ao acaso semelhante às moléculas de um gás em um recipiente. Se fizermos passar um plano imaginário perpendicularmente a um fio de cobre, elétrons de condução passarão pelo plano nos dois sentidos bilhões de vezes por segundo, no entanto não existirá um fluxo líquido de cargas e, consequentemente, não haverá uma corrente elétrica no fio. Se ligarmos, porém, as extremidades do fio a uma bateria, o número de elétrons atravessando o plano em um dos sentidos se tornará ligeiramente maior que o número de elétrons que atravessam o plano no sentido oposto; portanto, haverá um fluxo líquido de cargas, ou seja, surgirá uma corrente elétrica [12].

É importante atentar que, quando uma corrente flui no condutor, aqueles elétrons ainda se movem aleatoriamente, porém passam a ter também uma velocidade de deriva $\left(\vec{v}_{d}\right)$ no sentido oposto ao do campo elétrico que produz a corrente. Na verdade, de acordo com a Física Moderna, não é possível definir a posição de um elétron, nem faz sentido falar na trajetória do movimento de um elétron, mas é possível concluir que existe essa irregularidade, pois a velocidade média com que os elétrons se deslocam através do condutor é extremamente lenta. $\mathrm{O}$ módulo da velocidade aleatória é da ordem de $10^{6} \mathrm{~m} / \mathrm{s}$, enquanto que o da velocidade de deriva é da ordem de $10^{-4} \mathrm{~m} / \mathrm{s}$ ou ainda menor. Com uma velocidade de deriva tão pequena, surge o 
questionamento de como uma lâmpada acende imediatamente após ser ligado o interruptor. A explicação é que, ao fechar o interruptor, cria-se um campo elétrico (com velocidade próximo a da luz), em toda a extensão do circuito, o que faz estes elétrons livres (incluindo os da lâmpada incandescente), move-se quase que instantaneamente [13].

É importante destacar que a quantidade de elétrons é igual à quantidade de prótons (cargas negativas e cargas positivas respectivamente) dentro do fio, porém os prótons não se movimentam, pois estão fortemente ligados ao núcleo dos átomos, que se encontram mais ou menos presos em posições fixas. Deve-se lembrar também, de que só os elétrons livres (aqueles fracamente ligados ao átomo) constituem a corrente elétrica [14].

Dessa forma, quanto maior a quantidade de carga $\Delta \mathbf{q}$ que atravessa uma seção normal $\mathbf{S}$ de um condutor, no intervalo de tempo $\Delta \mathbf{t}$, mais intensa é a corrente de portadores de cargas que atravessa esse condutor. Sendo a quantidade de carga medida em coulombs $(\mathbf{C})$ e o intervalo de tempo em segundos (s), a unidade da intensidade da corrente elétrica no SI recebe é medida em ampère (A). Assim, define-se a intensidade da corrente elétrica $\mathbf{i}$, que atravessa a seção normal $\mathbf{S}$ do condutor através da equação 1 [15].

$$
\mathrm{i}=\frac{\Delta \mathrm{q}}{\Delta \mathrm{t}}
$$

Nos condutores sólidos, o sentido real da corrente elétrica é o sentido do movimento dos elétrons, pois são estes que se deslocam do potencial menor (polo negativo) para o potencial maior (polo positivo). Entretanto, devido a razões históricas, adotou-se um sentido convencional para a corrente elétrica, que é o deslocamento imaginário das cargas positivas do condutor. Portanto, no estudo da corrente elétrica o seu sentido é considerado o mesmo do campo elétrico no interior do condutor [16].

Um fio metálico, por ser condutor, contém grande quantidade de elétrons livres, cerca de $10^{22}$ por centímetro cúbico. Quando um fio, de cobre, por exemplo, está submetido a uma diferença de potencial, e um campo elétrico se estabelece em seu interior, os elétrons livres passam a avançar no sentido contrário ao do campo sofrendo inúmeras interações entre si e com os íons que formam a estrutura interna do condutor [17]. Portanto, o que leva os elétrons que estão ao longo de um fio a moverem-se constituindo uma corrente elétrica é o campo elétrico aplicado sobre estes, que os fazem reagirem simultaneamente, e não as interações que os elétrons sofrem. Na verdade, as colisões, repulsões e atrações a que os elétrons estão sujeitos durante seu percurso contribuem para torná-los mais lentos devido à resistência que oferecem ao seu movimento [14].

O condutor, dessa forma, ao mesmo tempo em que permite que os elétrons livres se movam através dele, também oferece certa resistência. Ao serem bombardeados pelos elétrons livres, os cátions do metal passam a oscilar com amplitudes maiores, o que se traduz em uma elevação da temperatura do fio. Com isso toda a energia potencial elétrica perdida pelos elétrons livres é convertida em energia térmica. Essa transformação de energia potencial elétrica em energia térmica recebe o nome de Efeito Joule [18].

A resistência elétrica é a capacidade de um objeto de opor-se à passagem de corrente elétrica, quando submetido a uma diferença de potencial [19]. Além disso, a resistência de um condutor depende de suas dimensões, temperatura e de sua particular condutibilidade. Fios grossos tem uma resistência menor do que os finos. Fios compridos tem maior resistência do que curtos. Fios de cobre tem menor resistência do que fios de aço com as mesmas dimensões. A resistência elétrica também depende da temperatura. Quanto menor a amplitude com que os átomos dentro de um condutor oscilam, menor a resistência que ele oferece ao fluxo de cargas. Para a maioria dos condutores, um aumento de temperatura significa um aumento de resistência [14].

Os condutores percorridos por corrente elétricas de menor intensidade oferecem maior dificuldade ao movimento dos portadores de carga elétrica, enquanto aqueles percorridos por correntes elétricas de maior intensidade oferecem menor resistência. Assim define-se a resistência elétrica $(\mathbf{R})$ de um condutor pela equação 2 [15].

$$
\mathrm{R}=\frac{\mathrm{V}}{\mathrm{i}}
$$


Em que $\mathbf{V}$ é a diferença de potencial nas extremidades do condutor e $\mathbf{i}$ é a intensidade da corrente elétrica que o atravessa. A unidade de resistência elétrica no SI deriva da razão volt/ampère e recebe o nome de ohm $(\Omega)$.

O valor da resistência elétrica de qualquer condutor não é constante, mas varia com a intensidade da corrente elétrica que o percorre. Entretanto, esse valor pode ser considerado constante no limite de determinados intervalos de variação da intensidade da corrente elétrica. Nessa situação, a diferença de potencial nas extremidades do condutor é diretamente proporcional à intensidade da corrente elétrica que o atravessa (neste caso temos a primeira lei de $\mathrm{Ohm}$ ). E o valor da resistência é a constante de proporcionalidade. Assim, a partir da definição de resistência elétrica, temos a equação 3 [15].

$$
\mathrm{V}=\mathrm{Ri}
$$

A equação 2, pode ser estendida para definir a resistência elétrica de um condutor qualquer, mesmo os não ôhmicos. Entretanto, neste último caso ainda que estejam a uma mesma temperatura o quociente dado já não será mais uma constante.

A resistividade elétrica é uma grandeza característica do material de que é constituído o resistor e depende também da temperatura que ele alcança. Conforme a Segunda Lei de Ohm a resistência elétrica $\mathbf{R}$ de um condutor homogêneo de seção transversal uniforme é proporcional ao seu comprimento $\mathbf{l}$, inversamente proporcional à área $\mathbf{S}$ de sua seção transversal e depende da resistividade elétrica $\boldsymbol{\rho}$, conforme a equação 4 [18].

$$
\mathrm{R}=\rho \frac{\mathrm{l}}{\mathrm{S}}
$$

Os valores da resistividade e resistência variam com a temperatura. No caso de metais, tal dependência é linear ao longo de uma larga faixa de temperaturas. Uma relação empírica para a dependência com a temperatura da resistividade de um metal é expressa pela equação 5 . Em que $\boldsymbol{\alpha}$ é uma constante denominada coeficiente térmico da resistividade elétrica, que depende do material que é feito o condutor, $\boldsymbol{\rho}$ é a resistividade do resistor na temperatura $\mathbf{T}, \boldsymbol{\rho}_{\mathbf{0}}$ a resistividade do resistor na temperatura $\mathbf{T}_{\mathbf{0}}$. Desprezando-se a dilatação térmica do resistor, a dependência da resistência $\mathbf{R}$ de um condutor com a temperatura pode ser aproximada pela equação 6 [13].

$$
\begin{aligned}
& \rho=\rho_{0}\left[1+\alpha\left(\mathrm{T}-\mathrm{T}_{0}\right)\right] \\
& \mathrm{R}=\mathrm{R}_{0}\left[1+\alpha\left(\mathrm{T}-\mathrm{T}_{0}\right)\right]
\end{aligned}
$$

É importante mencionar que para os metais puros, quando a temperatura aumenta, a resistividade também aumenta, ou seja, sempre $\alpha>0$. Isso ocorre porque o acréscimo na temperatura provoca uma maior agitação térmica dos elétrons e dos íons da rede cristalina, o que aumenta a probabilidade de choques entre estes e os elétrons, já o número de elétrons livres praticamente não varia. Outras substâncias, no entanto, como o silício, o germânio, o carbono etc., apresentam valores negativos para o coeficiente $\boldsymbol{\alpha}$. A resistência elétrica destas substâncias diminui quando elas são aquecidas. Isso ocorre porque o aumento da agitação térmica faz com que um grande número de elétrons se separe de seus átomos, tornando-se elétrons livres. Então, embora a mobilidade dos elétrons se torne menor, um aumento na temperatura provocará uma diminuição na resistência elétrica destes materiais, visto que a população de elétrons livres aumenta consideravelmente [20].

\section{RESULTADOS E DISCUSSÕES}

A fim de mostrar os cuidados no uso de algumas simulações na abordagem de conteúdos da Física, como o estudo de corrente elétrica em fios condutores, neste trabalho optou-se por realizar uma análise de algumas simulações disponibilizadas gratuitamente na plataforma virtual on-line disponível em htpp://phet.colorado.edu/pt_BR/. O Physics Education Technology $\left(\mathrm{PhET}^{\mathrm{TM}}\right)$ é um projeto da Universidade do Colorado dos Estados Unidos da América, idealizado para desenvolver simulações para diversas áreas das ciências exatas e naturais como a Física, por exemplo [21].

O site foi escolhido por ser bastante referenciado em artigos voltados para a aplicação de simulações no ensino de Física. As simulações são escritas em Java, Flash ou HTML5 e são 
disponibilizadas em diversos idiomas inclusive no português, podendo ainda ser executadas online ou baixadas gratuitamente por qualquer pessoa interessada.

Para mostrar as consequências do uso incorreto de alguns simuladores no ensino de Física como, por exemplo, o "Movimento de cargas elétricas em um fio condutor" foram escolhidos três simuladores: simulador "Sinal de Circuito", simulador "Kit de construção de circuito (DC)" e simulador "Circuito Bateria-Resistor".

\subsection{SIMULADOR: "SINAL DE CIRCUITO"}

O escopo principal desta simulação é explicar situações do cotidiano. Como, por exemplo, por que as luzes se acendem em um quarto assim que é ligado o interruptor? Na simulação, como se pode observar, os elétrons estão representados fora de escala, por esferas azuis (fig. 1). O professor poderá utilizar este simulador para trabalhar o conceito de corrente elétrica, sentido real e convencional da corrente elétrica, campo elétrico e diferença de potencial.

\subsubsection{SIMPLIFICAÇÕES E EXAGEROS:}

\section{No circuito em geral:}

- Os elétrons aparecem em quantidade simplificada e com tamanhos fora de escala, dessa forma o professor deverá alertar ao discente, que na verdade a quantidade de elétrons livres, que constituem a corrente elétrica é na ordem de aproximadamente $10^{22}$ por centímetro cúbico, em um fio condutor.

- O circuito não mostra os cátions, nem simula as interações que ficam ocorrendo entre estes e os elétrons.

- O circuito tanto ligado como desligado apresenta alguns elétrons mais próximos, enquanto outros estão mais espaçados, como se o campo elétrico atuante fosse inomogêneo, em ambas as situações, o que é um erro.

\section{Circuito aberto:}

- Quando circuito se encontra aberto, alguns elétrons realizam um pequeno movimento vibratório, enquanto outros não realizam movimento algum, sendo que na realidade a ordem da velocidade dos movimentos aleatórios é aproximadamente $10^{6} \mathrm{~m} / \mathrm{s}$.

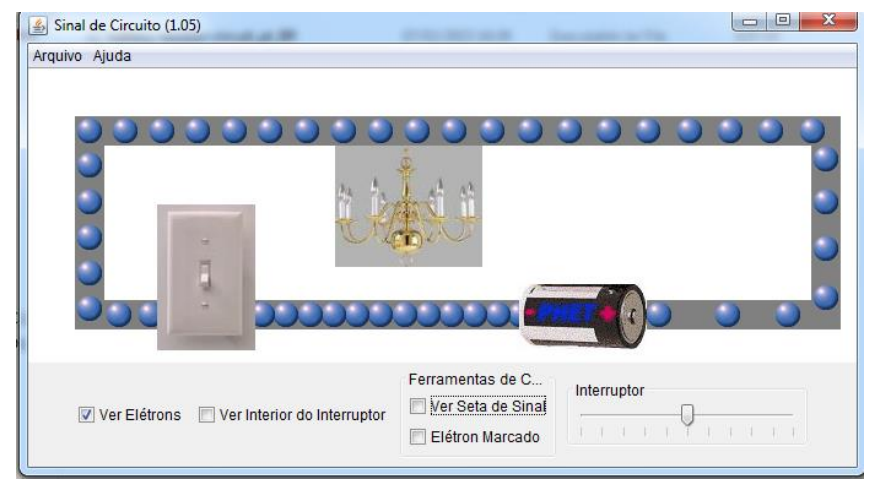

Figura 1: Simulador "Sinal de Circuito" circuito aberto

\section{Circuito fechado:}

- A velocidade de deriva com que os elétrons estão se movimentando no circuito, não condiz com o que se observa experimentalmente, que é uma velocidade de arraste na ordem de $10^{-4} \mathrm{~m} / \mathrm{s}$.

- Os elétrons são representados se movimentando em "fila indiana", o que é um erro, pois estes realizam muitas interações entre si e com os cátions, dessa forma, seu movimento ocorre guiado pelo campo elétrico, porém, de forma irregular. 
- Ao fechar o circuito as luzes se acedem num intervalo de tempo perceptível pelos sentidos, ou seja, o campo não surge de forma imediata, como deveria ocorrer.

- Os elétrons não se movem todos ao mesmo tempo quando o circuito é acionado, o que não está correto, pois a velocidade do campo elétrico responsável por orientar os elétrons e aproximadamente próximo à velocidade da luz.

- Quando se clica no ícone "ver seta de sinal", aparece uma seta que indica o sentido real das cargas elétricas, e não o sentido da corrente. O professor deve alertar para o educando a diferença entre corrente real e corrente convencional, já que no simulador não é especificado o significado da seta.

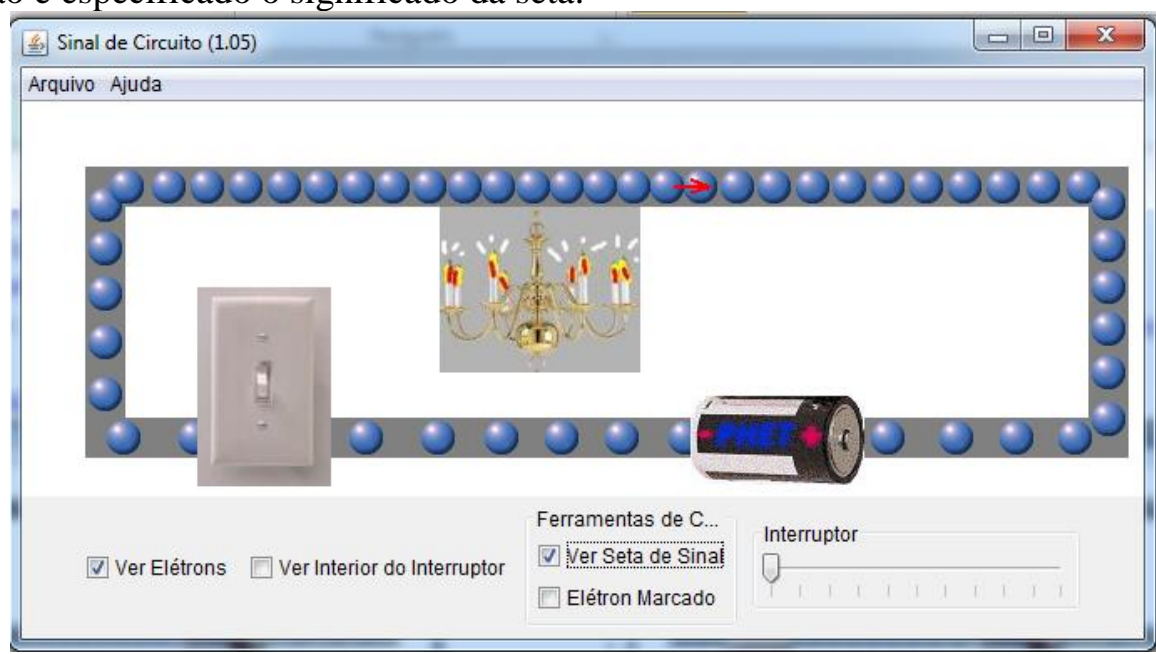

Figura 2: Simulador "Sinal de Circuito"circuito fechado

\subsection{SIMULADOR: "KIT DE CONSTRUÇÃO DE CIRCUITO (DC)"}

Este simulador serve para construir através de simulações, circuitos básicos envolvendo resistores, lâmpadas, baterias e interruptores, podendo ainda realizar medições com amperímetro e voltímetro (fig. 3). A vantagem deste simulador deve-se ao fato do próprio aluno construir os circuitos, ou seja, permite uma maior interatividade do aluno.

\subsubsection{SIMPLIFICAÇÕES E EXAGEROS:}

\section{No circuito em geral:}

- Como o tamanho e a quantidade de elétrons estão longe da realidade, o professor deve esclarecer estes itens, inclusive fazendo um paralelo entre a visão do elétron pela Física clássica e também a luz da mecânica quântica.

- O circuito não mostra as interações entre cátions e elétrons.

\section{Circuito aberto:}

- Não é modelada a resistência que os elétrons enfrentam durante seu percurso, devido à rede cristalina do fio condutor.

- Quando o circuito está desligado os elétrons se mostram sem nenhum movimento, o que é errado, pois os elétrons livres se encontram em altíssimas velocidades, porém sem fluxo líquido de cargas em uma dada direção, como pode ser visto na figura 3. 


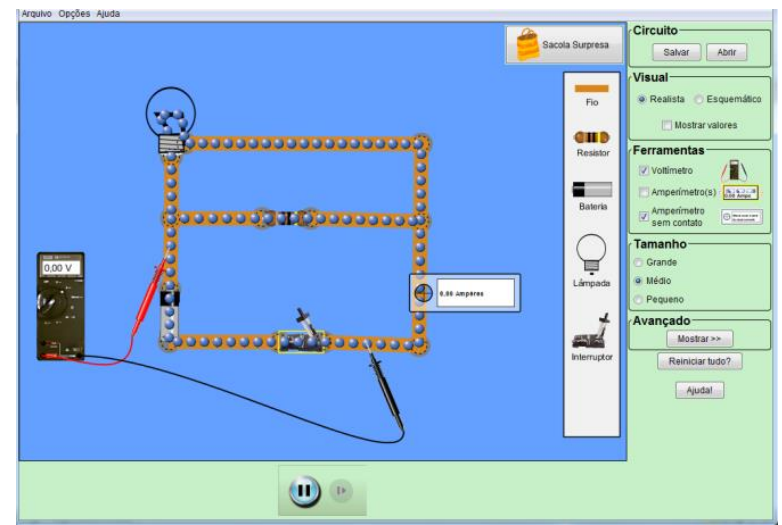

Figura 3: Simulador "Kit de construção de circuito (DC)" circuito aberto

\section{Circuito fechado:}

- A velocidade dos elétrons não condiz com a realidade, num sistema real a velocidade de deriva é mais lenta.

- Os elétrons são apresentados se movimentando enfileirado o que não ocorre num sistema real.

- Conforme algumas medições realizadas com o amperímetro e o voltímetro, verifica-se que ambos não alteram as medições, dessa forma o professor deve esclarecer que estes se tratam de modelos ideais.

- Quando se aumenta a resistência, o que se observa visualmente é apenas uma redução na velocidade dos elétrons, dessa forma o educador deve esclarecer os motivos dessa redução já que o simulador não mostra.

- Quando o circuito está fechado os elétrons se movimentam de forma organizada em apenas um único sentido, ou seja, o simulador não aborda a velocidade aleatória dos elétrons, como pode ser visto na figura 4.

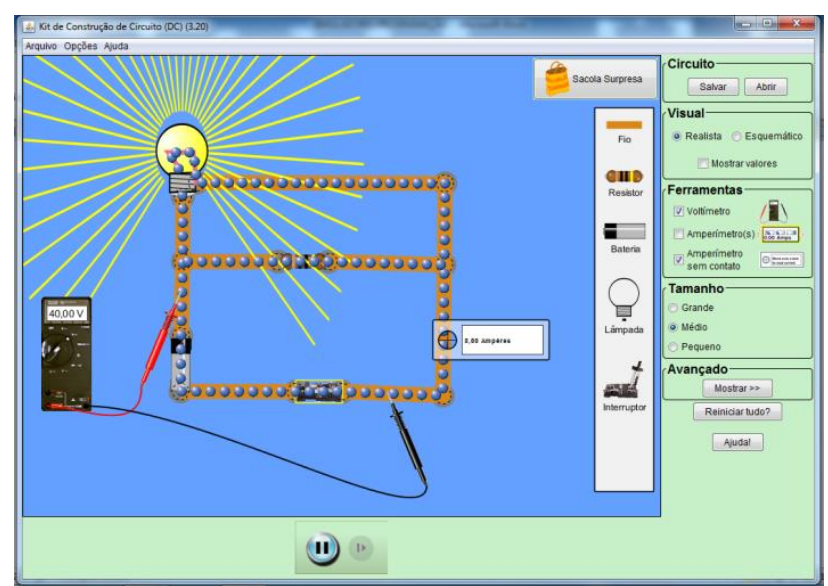

Figura 4: Simulador "Kit de construção de circuito (DC)" circuito fechado

\subsection{SIMULADOR: "CIRCUITO BATERIA-RESISTOR"}

Este simulador aborda os conceitos de resistência elétrica, fluxo de elétrons, tensão e Efeito Joule.

\subsubsection{SIMPLIFICAÇÕES E EXAGEROS:}

\section{No circuito em geral:}

- Este simulador assim como os demais discutidos também apresenta os elétrons com tamanho e movimento de forma simplificada. 
- O circuito tanto ligado como desligado não apresenta os elétrons distribuídos de forma homogênea, o que visualmente é possível perceber uma densidade desigual de portadores de carga em trechos diferentes do fio.

\section{Circuito aberto:}

- Quando o circuito é desligado, de maneira errônea é mostrado tantos os elétrons (em azul) como cátions (em verde) sem movimento algum, figura 5.

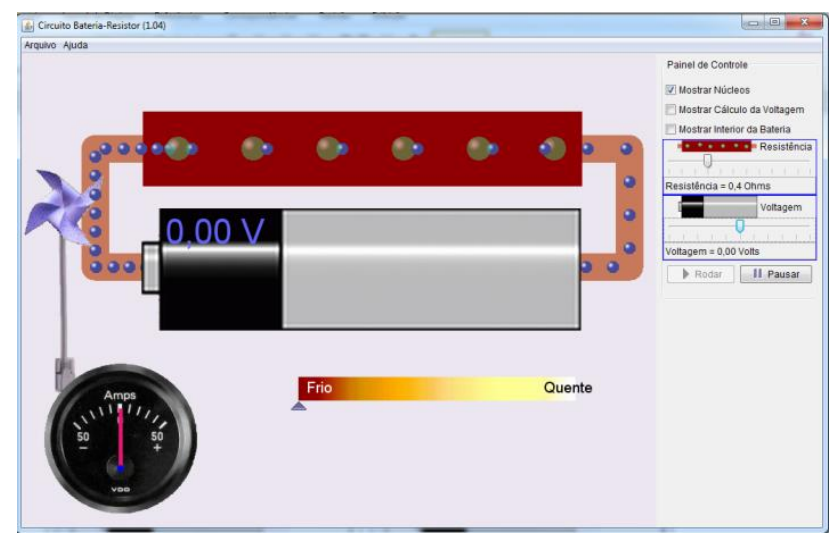

Figura 5: Simulador "Circuito Bateria-Resistor" circuito desligado

\section{Circuito fechado}

- Com o circuito fechado, são apresentados os cátions que interferem na movimentação dos elétrons, no entanto, a movimentação dos cátions e elétrons não estão corretas, os elétrons, por exemplo, interagem entre si e com os cátions, mas não são observados, consideráveis mudanças de rota, os elétrons praticamente não mudam suas trajetórias. É possível apenas verificar que estes sofrem certa resistência ao interagirem com os cátions.

- É importante também que o professor explique o porquê das cargas positivas não se movimentarem no campo elétrico constituíndo assim uma corrente contrária à movimentação dos elétrons, e também o porquê de nem todos os elétrons participarem da formação da corrente elétrica mais apenas os elétrons livres.

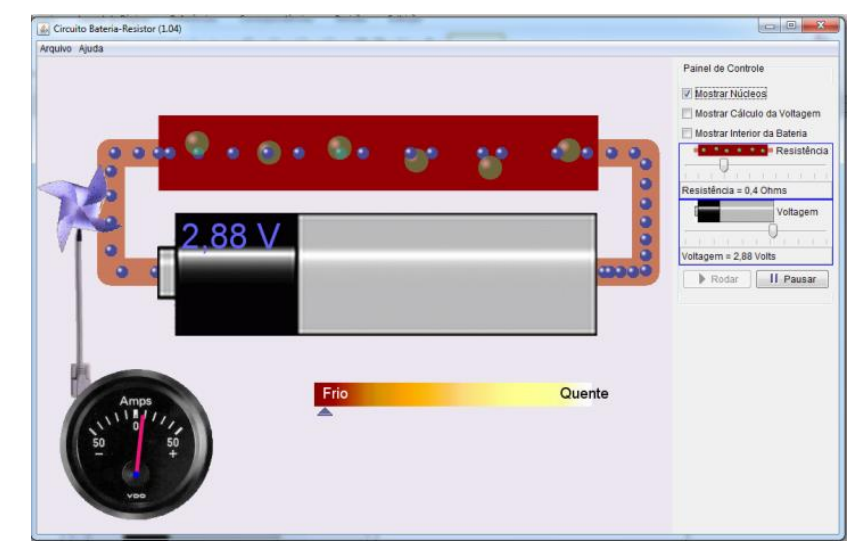

Figura 6: Simulador "Circuito Bateria-Resistor" circuito fechado

- Quando se aumenta a voltagem do sistema observasse os seguintes pontos: uma maior velocidade dos elétrons, um aumento da amplitude de vibrações dos cátions o que aumenta a resistência elétrica, um aumento da corrente elétrica e o um aumento da temperatura do sistema (efeito Joule). No entanto, outros fenômenos relacionados que não foram contemplados na simulação podem ser abordados pelo professor como: Explicar porque alguns materiais diminuem a resistência com o aumento de temperatura 
e abordar a influencia da dilatação térmica do material na corrente elétrica, como pode ser visto na figura 7.

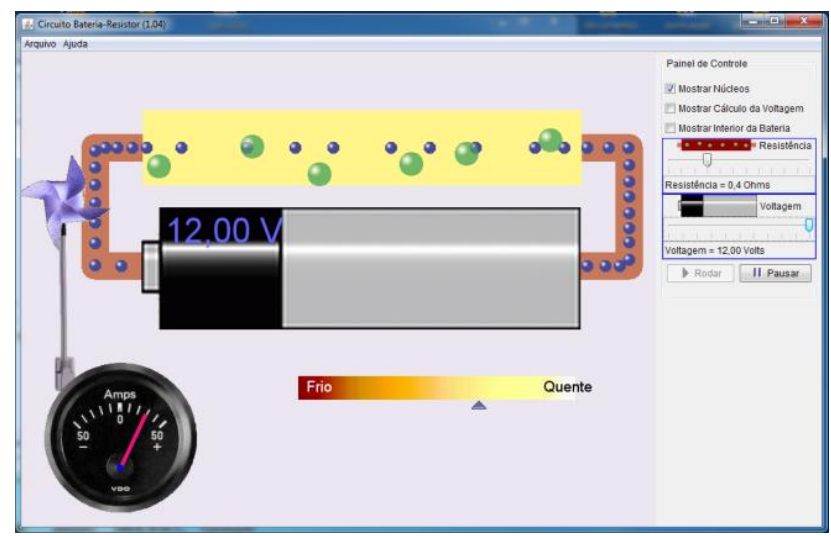

Figura 7: Simulador "Circuito Bateria-Resistor" aumento de voltagem

\section{CONCLUSÃO}

O trabalho aborda os cuidados pedagógicos necessários para o uso de três simuladores de corrente elétrica, ressaltando as consequências do uso incorreto de alguns simuladores no ensino de Física: o "Movimento de cargas elétricas em um fio condutor" foram escolhidos três simuladores: simulador "Sinal de Circuito", simulador "Kit de construção de circuito (DC)" e simulador "Circuito Bateria-Resistor".

Nos três simuladores analisados, verificou-se que as simplificações que mais podem levar o aluno a interpretações errôneas se deve ao fato de como a corrente elétrica é produzida. Desse modo, se o aluno não for bem instruído, pode analisar as simulações apenas pelo visual. Que na verdade, apresentam os elétrons se movimentando de forma organizada em fileiras quando o circuito se encontra fechado e elétrons também sem movimento algum ou com uma vibração muito pequena quando o circuito está aberto, ou seja, quando não existe corrente elétrica. Além de não compreenderem corretamente as interações que os elétrons realizam entre si e com a estrutura cristalina do material do fio condutor que explicam os fenômenos de resistência elétrica e efeito Joule.

Neste desafio de ampliar aprendizagem e torná-la significativa, as tecnologias surgem como uma ferramenta pedagógica fornecendo um ambiente, onde o aluno manipula programas, simula diversas situações e com autonomia constroem ou consolida conceitos da física. Porém, o professor deve estar atento às orientações para evitar interpretações errôneas.

\section{AGRADECIMENTOS}

Os autores agradecem a Coordenação de Aperfeiçoamento de Pessoal de Nível Superior (CAPES) pelo aporte financeiro.

\section{REFERÊNCIAS}

1. Moraes AM, Moraes IJ. A avaliação conceitual de força e movimento. Revista Brasileira de Ensino de Física. [internet]. 2000. [acesso em 2015 nov 12]; 25 (3): 232-246. Disponível em http://www.scielo.br/scielo.php?Script=sci_arttext\&pid=S1806-11172003000200007.

2. Ferreira A. Estratégias Pedagógica em Aulas de Ciências e de Física e a Teoria de Ausubel, 2000. Disponívelem<http://www.sbf1.sbfisica.org.br/eventos/snef/xvii/sys/resumos/04841.pdf $>$.Acesso em 25 de maio de 2015.

3. Moreira MA, Masini EFS. Aprendizagem significativa. 2. ed. Rio de Janeiro: Centauro; 2002.

4. Brasil, Secretaria de Educação Básica. Orientações curriculares para o Ensino Médio. v. 2: Ciências da Natureza, Matemática e Tecnologias. Brasília, DF: MEC; 2006. 
5. Carnoy M. A vantagem acadêmica de Cuba: por que seus alunos vão melhor na escola. São Paulo: Editora; 2009.

6. Arruda JRC. Um modelo didático para enseanzy y aprendizaje de la Física. Revista Brasileira de Ensino de Física. [internet]. 2003. [acesso em 2015 nov 11]; 25 (1): 86-104. Disponível em http://www.sbfisica.org.br/rbef/pdf/v25_86.pdf

7. Medeiros A, Medeiros CF. Possibilidades e limitações das simulações computacionais no ensino da física. Revista Brasileira de Ensino de Física. [internet]. 2002. [acesso 2015 jan 10];24(2):7786. Disponível em http://www.sbfisica.org.br/rbef/pdf/v24_77.pdf.

8. Fiolhais C, Trindade J. Física no Computador: o Computador como uma Ferramenta no Ensino e na Aprendizagem das Ciências Físicas. Revista Brasileira de Ensino de Física. [internet]. 2003. [acesso 2015 jan 10]; 25(3): 259-272. Disponível em http://www.sbfisica.org.br/rbef/pdf/v25_259.pdf.

9. Lévy P. As tecnologias da inteligência: o futuro do pensamento na era da informática. Rio de Janeiro: 34 Ltda; 1993. 208p.

10. Oliveira R. Informática educativa: Dos planos e discursos à sala de aula. 15 ed. Campinas (SP): Papirus; 1997. $176 \mathrm{p}$.

11. Chaves EOC. O Uso de Computadores em Escolas: Fundamentos e Críticas [internet]. São Paulo: Scipione; 1988. [acesso 2015 jan 10] Disponível em http://www.ich.pucminas.br/pged/db/wq/wq1/local/ec_scipione.htm.

12. Halliday D, Resnick JW. Fundamentos de Física: óptica e física moderna. Rio de Janeiro: LTC; 2010. p.416.

13. Bauer W, Westfall GD, Dias H. Física Para Universitários: eletricidade e magnetismo. Porto Alegre: AMGH; 2012. 386 p.

14. Hewitt PG. Física conceitual. 9 ed. Porto Alegre: Bookmam; 2002.

15. Gaspar A. Física 3: eletromagnetismo e física moderna. 2 ed. São Paulo: Ática; 2009. p. 352.

16. Bonjorno RA, Bonjorno JR, Bonjorno V, Ramos CM. Física Completa: ensino médio: volume único. São Paulo: FTD; 2000.

17. Bonjorno JR, Ramos CM, Alves LA. Física: Eletromagnetismo - Física Moderna. São Paulo: FTD; 2010.

18. Biscuola GJ, Bôas NV, Doca RH. Física: ensino médio volume 3. São Paulo: Saraiva; 2010.

19. Fuke LF, Kazuhito Y. Física para o Ensino Médio. São Paulo: Saraiva; 2010.

20. Luz AMR, Álvares BA. Curso de Física. 6 ed. São Paulo: Scipione; 2005.

21. Universidade do Colorado (Org.). Simulações Interativas PhET. [internet]. [acesso 2015 jan 20 ]. Disponível em https://phet.colorado.edu/pt_BR/simulations/category/physics. 